\title{
METÁFORAS ZOONÍMICAS DEL DICCIONARIO DE COSTARRIQUEÑISMOS DE ARTURO AGÜERO CHAVES (1996)
}

\author{
Marjorie Jiménez Castro*
}

\begin{abstract}
RESUMEN
El tema de las metáforas relacionadas con los animales ha sido poco estudiado en el español de Costa Rica. El trabajo que presentamos analiza 324 metáforas zoonímicas del Diccionario de costarriqueñismos de Arturo Agüero Chaves (1996) siguiendo principalmente los postulados teóricos de Lakoff y Johnson (1998). En este trabajo interesa destacar la metáfora como vehículo de valores y antivalores culturales de una comunidad de habla.

Palabras clave: metáfora, costarriqueñismos, lexicografía, Arturo Agüero Chaves, fraseología zoonímica.
\end{abstract}

\begin{abstract}
Metaphors related to animals have been a topic with few studies in the Costa Rican Spanish. The present work analyzed 324 zoonimics metaphors from the Diccionario de costarriqueñismos by Arturo Agüero Chaves (1996) following the theoretical principles of Lakoff and Johnson (1998). A purpose of the present work is to highlight the metaphor as a vehicle of cultural values and antivalues of a speaking community.

Key Words: metaphors, costarriqueñismos, lexicography, Arturo Agüero Chaves, zoonimic phraseology.
\end{abstract}

\section{Aspectos generales}

El trabajo que presentamos a continuación consiste en un análisis de la metáfora como un recurso lingüístico empleado en la construcción del fraseologismo zoonímico registrado en el Diccionario de costarriqueñismos de Agüero $^{2}$. Para la elaboración del trabajo fue necesario, primeramente, escanear cada una de las páginas del DCA para hacer más simple la identificación de las unidades fraseológicas referidas a animales. Se identificó un total de 3236 unidades pluriverbales de las cuales 324 están relacionadas con el tema en estudio. Posteriormente, el corpus fue ordenado a partir del sustantivo zoonímico. Por último, se procede a analizar las metáforas de acuerdo con los criterios teóricos de Lakoff y Johnson (1998), Echevarría (2003), Kekié (2008) y Pamies (2002) sobre los mecanismos que emplea el hablante para transformar situaciones complejas en fórmulas lingüísticas de fácil comprensión.

\section{Estudios sobre la fraseología zoonímica en Agüero (1996)}

Sobre el tema específico de la fraseología zoonímica en Agüero (1996), 
solamente encontramos la referencia "Creación metafórica y lexicográfica en el Diccionario de Costarriqueñismos de Arturo Agüero" (Sánchez Mora, 2007).

La investigación de Sánchez Mora (2007) está basada en un corpus extraído de la letra $\mathrm{C}$ del DCA. Sobre este corpus trabajó con 102 lemas que corresponden a unidades léxicas cuya significación es el resultado de un proceso metafórico, las agrupó en campos semánticos y, finalmente, consideró 76 lemas, que resultaron de los tres grupos donde se registraron más metáforas. El autor las dividió en 28 metáforas animales, 26 metáforas de plantas y 22 metáforas vitandas y escatológicas.

Del primer grupo, Sánchez Mora destaca que 21 de las metáforas emplean unidades léxicas referidas a animales para aludir a conductas, actividades y partes del cuerpo con una connotación negativa, por ejemplo, "el lexema caballo aplicado a un ser humano destacaría su ignorancia y torpeza, calandria su cobardía y debilidad, camello su sometimiento" (Sánchez Mora, 2007: 147). En este grupo se incluyen también unidades léxicas que tratan de la animalización de la mujer, de acuerdo con el autor, muy recurrentes en el DCA.

Además, Sánchez Mora señala que, a pesar del gran peso que tiene la metáfora animal, es lamentable que no se le haya dedicado gran atención, pues, aún en nuestro tiempo, son muy pocos los estudios realizados sobre el tema.

Para el autor, la mayoría de las metáforas animales hacen referencia a defectos humanos o son utilizadas con el fin de ridiculizar algo o especialmente a alguien, pues en su mayor parte hacen referencia a la fealdad física, a la estupidez y a la maldad.

Con respecto al segundo grupo de metáforas, el relacionado con las plantas, señala que "el gran número de metáforas vegetales da cuenta de la indudable importancia de las plantas en la cotidianidad de los seres humanos, en especial si se considera que, al menos hasta la década de 1970, la sociedad costarricense fue de carácter eminentemente rural" (Sánchez Mora, 2007: 148).

El tercer grupo corresponde a los significados y significantes vitandos $y$ escatológicos. En este grupo se mencionan las metáforas sexuales, que, de acuerdo con el análisis, se dejaron de utilizar, lo que implica "una rápida renovación en la que cada generación emplea sus propios procedimientos sustitutivos" (Sánchez Mora, 2007: 148).

Según este autor (2007: 148-149), en el DCA se emplean tres estrategias para definir las metáforas: la sinonimia, la conversión de la metáfora en un símil y combinar la definición enciclopédica con la hipótesis explicativa del mecanismo metafórico.

A pesar de que el artículo se basa únicamente en las metáforas zoonímicas de la letra $C$ del Diccionario de Agüero, lo consideramos un valioso punto de partida para nuestra investigación.

\section{Metáfora y fraseología zoonímica}

Tradicionalmente la metáfora se ha estudiado como un recurso retórico utilizado por los escritores; un acto de inspiración creadora que consiste en la capacidad de relacionar conceptos que en apariencia no lo están. Su estudio se ha centrado en determinar el juego de sentido que se produce en las comparaciones tácitas pero siempre en el campo de la literatura; sin embargo, en las últimas décadas han aparecido investigaciones que han despojado a las musas del poder de las metáforas y nos han dotado a todos de esa capacidad creadora. Precisamente, George Lakoff y Mark Johnson (1998) se han interesado, a partir de 1970, en explicar, por un lado, la metáfora como un mecanismo para aprehender la realidad y, por el otro, la naturaleza de los sistemas conceptuales. Para los autores, la metáfora nos permite estructurar conceptos a partir de otros. La forma en que realizamos este proceso depende de nuestras experiencias directas con el mundo a través de nuestro cuerpo. Por lo tanto, las metáforas impregnan el lenguaje cotidiano formando una red compleja e interrelacionada tanto para las nuevas metáforas como para las consideradas fósiles. La existencia de esta red afecta a las representaciones internas, a la visión de mundo que tienen los hablantes. En su obra Metáforas 
de la vida cotidiana (1998: 13), presentan y analizan tres tipos de conceptos metafóricos: las metáforas orientacionales (arriba-abajo) Ejemplo: Me levantó el ánimo; las metáforas ontológicas (entidad, sustancia, contenedor) Ejemplo: La mente es una máquina (voy a perder el control); y la metáforas estructurales, que permiten utilizar un concepto muy estructurado para estructurar otro; ejemplo: El trabajo es un recurso o la discusión es una guerra. Estas metáforas corresponden a tres áreas de experiencia que nos permiten comprender otras experiencias.

Constantemente, los hablantes emplean una serie de metáforas como un mecanismo de aprehender situaciones complejas. Los hablantes crean un sistema conceptual basado en su relación con el ambiente y con su cultura, y esa experiencia cotidiana fija, a través de metáforas, la realidad; pero también puede proporcionar, mediante metáforas imaginativas y creativas, nuevas formas de comprender la existencia. Las metáforas nos hablan de nuestro entorno, de los valores y de los antivalores de la sociedad. En relación con esta perspectiva de análisis, encontramos la propuesta de George Lakoff y Mark Johnson (1998) para quienes las metáforas son una herramienta de conocimiento de la naturaleza humana, por lo tanto, forman parte del sistema conceptual:

\begin{abstract}
Las metáforas tienen implicaciones por medio de las cuales destacan y hacen coherentes ciertos aspectos de nuestra experiencia. Una metáfora determinada puede ser la única forma de destacar y organizar de forma coherente precisamente esos aspectos de nuestra experiencia. Las metáforas pueden crear realidades sociales. Una metáfora puede así convertirse en guía para la acción futura. Estas acciones desde luego se ajustarán a la metáfora. Esto reforzará a su vez la capacidad de la metáfora de hacer coherente la existencia. En este sentido, las metáforas pueden ser profecías que se cumplen. (Lakoff y Johnson, 1998: 198).
\end{abstract}

Para los autores, el hablante establece una serie de relaciones entre aquellas situaciones concretas o fáciles de entender con las más complejas y abstractas; y en este proceso se van creando una serie de relaciones y de conceptos nuevos. Las experiencias cotidianas a las que se enfrenta el hablante y su forma de relacionarse con el mundo le permite crear esquemas mentales para organizar su realidad, también le permite establecer asociaciones con situaciones corporales nuevas. Lakoff y Johnson (1998:51) explican que el hablante ha identificado, a través de su experiencia física y cultural, que arriba es positivo y abajo es negativo, de ahí surgen expresiones metafóricas como se me levantó la moral para transmitir un estado de bienestar o satisfacción o mi moral cayó por los suelos para indicar tristeza. Los investigadores han encontrado que los hablantes establecen comparaciones entre las sensaciones corporales y otras situaciones que sugieren bienestar, como la virtud, la salud y la fuerza, con estar arriba; y situaciones asociadas al malestar, como la enfermedad, el vicio y el control, con abajo (Lakoff y Johnson, 1998: 51-53).

Los autores citados por Pérez (2004: 646) afirman que los hablantes poseen una serie de esquemas mentales abstractos llamados mapping y que gracias al conocimiento de las metáforas conceptuales subyacentes o mapping, se construyen las expresiones metafóricas:

El significado figurado de las unidades fraseológicas está motivado por el conocimiento tácito de los hablantes de las metáforas conceptuales subyacentes. Estas metáforas conceptuales forman parte de la conexión entre un modismo y su significado figurado y constriñe la forma como las personas los comprenden. La metáfora es el mapping que resulta del cruce de dos dominios mientras que la expresión metafórica sería cualquiera de las expresiones que se pueden construir a partir de este mapping.

Echevarría (2003), siguiendo a Lakoff, señala que las metáforas conceptuales son esquemas abstractos que permiten agrupar expresiones metafóricas (casos individuales). Por ejemplo, una metáfora conceptual podría ser que lo alto es la virtud y lo bajo es el vicio. Una expresión metafórica que se desprende de este esquema mental o mapping es Ella tiene elevados pensamientos para indicar su altruismo o Cayó en el abismo de las drogas.

Partiendo del hecho que la metáfora desempeña un papel fundamental no solo en el enriquecimiento del caudal léxico, sino 
también del fraseológico, siendo el proceso de metaforización la vía principal que conduce a la formación de la unidades fraseológicas (Tristá, 1985: 63), Pamies (2002) estructura la propuesta de clasificación de Lakoff y Jhonson con el fin de trabajar con corpus de metáforas fraseológicas y elabora una propuesta metodológica. Esta propuesta nos parece pertinente para la investigación puesto que podemos agrupar la fraseología zoonímica del DCA a partir de dominios o campos conceptuales y clasificarlos a través de las imágenes que generan. La propuesta consiste en clasificar las unidades fraseológicas a partir de los conceptos que abordan. En el primer nivel se encuentra el concepto principal (dominio meta); en el segundo, las imágenes generales que se generan del concepto (dominio fuente o grupo de dominios fuente); en el tercero, las categorías específicas de la imagen general (archimetáforas); y en el cuatro, las metáforas particulares (Pamies, 2002: 14). Veamos un ejemplo de esta propuesta:
En este ejemplo se clasifican algunas expresiones metafóricas orientacionales; por eso se habla de los movimientos que puede producir el miedo en el ser humano. El miedo es el concepto abstracto o mapping y se manifiesta a través de sensaciones corpóreas traducidas en expresiones metafóricas que se basan en el movimiento hacia abajo y hacia arriba (bajarse la sangre a los talones y ponerse los pelos de punta). La temperatura implica también un movimiento de arriba y abajo (tener hormigas en la cola y helarse la sangre).

A partir de esta clasificación podemos crear diversos campos semánticos a partir de las frases zoonímicas del Diccionario de costarriqueñismos de Arturo Agüero. Además, los estudios de las unidades fraseológicas desde una perspectiva metafórica nos proporcionan información relevante sobre la comunidad de hablantes y de los procesos de formación cultural, por esta razón la fraseología metafórica se considera también, como un instrumento de cognición humana (Olza, 2009:156).

ESQUEMA 1

Propuesta metodológica de Pamies

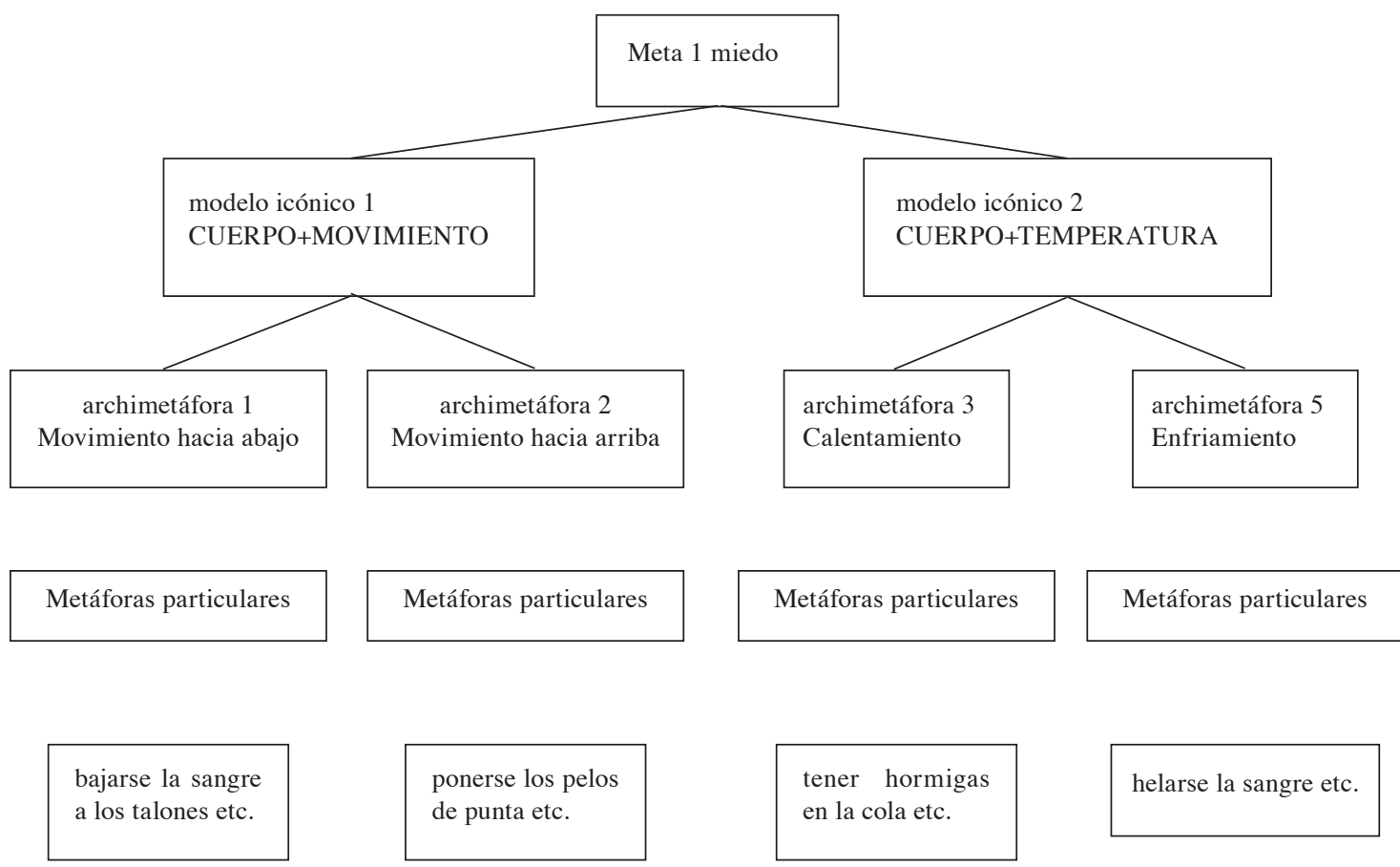




\section{Las metáforas zoonímicas: un acercamiento a la vida cultural}

Las metáforas zoonímicas surgen a partir de una serie de observaciones y relaciones establecidas del ser humano con los animales. Las personas han llegado a determinar cuáles de ellos son peligrosos o confiables, tercos o sumisos, etc. A partir de estas observaciones el hablante construye una serie de producciones lingüísticas comparativas entre la forma de vivir, alimentarse y actuar de los animales, con la de las personas. Estas construcciones léxicas son precisamente las que denominamos metáforas zoonímicas. Siguiendo a Kekié (2008:108), las metáforas zoonímicas son aquellas alusiones metafóricas o alegóricas de un animal para referirse a una conducta o a una característica del hombre, de una planta o de otro animal. Estas expresiones metafóricas pueden estar compuestas por una frase como "a caballo regalado no se le mira el colmillo" o por dos palabras como "culebra lora".

Como ya se ha mencionado en el capítulo 3 de esta investigación, y de acuerdo con la autora, nuestra forma de relacionarnos con el entorno, la experiencia directa, corporal, psicomotriz, nos ayuda a comprender, a través de las metáforas, otras realidades más abstractas y lejanas que no se podrían entender a simple vista. Toda esa experiencia cotidiana está impregnada de la cultura popular y, según Kekié (2008), queda plasmada en las unidades fraseológicas de la lengua. De acuerdo con lo anterior, tenemos dos formas de acercarnos al análisis de la metáfora: por un lado, está la que nos habla de la manera en que nos acercamos a la realidad $\mathrm{y}$, por el otro, el aspecto cultural que determina cómo percibimos los acontecimientos de la vida cotidiana. Kekié (2008:110-111) establece tres tipos de motivación semántica en las unidades fraseológicas metaforizadas:

1. Motivación icónica o metáfora conceptual que surge de mecanismos universales -reposa sobe los conocimientos que tenemos del mundo y es directamente deducible de la percepción y experiencia. El modelo descriptivo sería: experiencia - modelo icónico - archimetáfora metáfora particular.
2. Motivación simbólica, o metáfora cultural donde es el símbolo cultural lo que motiva una expresión - se basa en conocimientos culturales, convencionales, costumbres, mediados por las creencias colectivas y el aprendizaje. El modelo descriptivo sería: trasfondo cultural - culturema (entendido como símbolo + simbolizado) - metáfora particular.

3. Motivación metafórica, metáfora en cadena o metáfora metalingüística, la fuente de una metáfora no solo puede ser una experiencia directa, o un símbolo preexistente, sino también otra metáfora.

Específicamente del corpus en estudio podemos decir que las metáforas zoonímicas que aparecen en el DCA, evidencian una profunda y minuciosa observación de las características animales, su forma de vida, sus destrezas y limitaciones. Estas observaciones son incorporadas a la cotidianidad como una forma de explicar las situaciones a las que se enfrenta el hablante. No obstante, hay que tener claro que muchas de esas observaciones están determinadas por valores culturales, esto es, experiencia de vida, por lo tanto, pueden variar de una comunidad a otra. Así por ejemplo, en la fraseología zoonímica estudiada nos encontramos que un animal como el gato, que tiene atributos como la astucia y refiere a situaciones difíciles e incómodas, en otras lenguas, como el serbio, representa la lujuria, la hostilidad, la crueldad, la traición y el desprecio, según el estudio de Kekié (2008) titulado El lenguaje figurado con zoonímicos en serbio. De acuerdo con este, la vaca simboliza la fertilidad, el amor materno, la alimentación; la mula, el silencio; sin embargo, en los ejemplos encontrados los dos animales representan la vagancia y la estupidez. Es importante señalar que estos atributos van cambiando a través del tiempo; el gato, por ejemplo, de acuerdo con anotaciones que hicieron los encuestados, hoy ya no es registrado como complicación sino más bien como la agilidad y la astucia. De ahí que podemos distinguir metáforas que son legitimadas como tales y por lo tanto, podrían encontrarse en otras lenguas, otras que 
responden a situaciones muy locales y otras que están relacionadas con situaciones culturales particulares como las tradiciones, por ejemplo. Del primer grupo que se refiere a metáforas que se encuentran en otras lenguas se pueden anotar aquellas que nos hablan de la fidelidad del perro o la estupidez del burro, la laboriosidad de la hormiga y la abeja o el loro parlanchín:

\section{Perro faldero \\ Parecer una hormiga \\ Ser muy avispa \\ Ratón de biblioteca \\ Parecer una calandria \\ Ser o parecer un pajarito \\ Ser o parecer una lora}

Sobre este tema, concluimos, tal y como lo hace Kekié (2008: 127), que estas metáforas se originaron a partir de la observación directa o sobre un conocimiento subjetivo sobre un animal que luego se transmitió como un valor simbólico de una cultura común.

Con respecto a las metáforas que se generan en ámbitos más reducidos, tenemos, por ejemplo, situaciones relacionadas con la naturaleza o especies de animales propias de algunas regiones del país, como es el caso de un tipo de molusco llamado concha de vaca o la ju de león para referirse a un pájaro que anunciaba la proximidad del tigre en lugares montañosos.

Sobre las metáforas originadas a partir de una actividad cultural o para la comprensión de las cuales se requiere de información sobre actividades sociales relacionadas con el sentido de la metáfora, podemos citar del corpus los siguientes ejemplos:

buey. carreta sin bueyes (la). Fantasma nocturno que según la conseja popular es una carreta que sin bueyes rueda por los caminos rurales. Se cree que en ella va el Diablo, porque tras de sí va dejando una estela de chispas y un olor a azufre (Agüero, 1996: 58).

caballito. a caballito. $m$. adv. Montar o llevar a uno a caballito significa montarlo o llevarlo a horcajadas en la espalda. Especialmente se monta así a los niños (Agüero, 1996: 43). caballo. llevar caballo. fr. fig. En el juego de dados llamado virgen (V.), llevar más puntos un jugador sobre los otros que intervienen en la partida (Agüero, 1996: 43).

pájara. pájara pinta. 2. Ronda de niños que empieza así: "Estaba la pájara pinta, sentadita en su verde limón, con el pico recoge la hoja, con la cola recoge la flor..." (Agüero, 1996: 238).

En realidad, ejemplos como los anteriores son pocos en el corpus de esta investigación; la gran mayoría surgen de experiencias sensoriales y de la observación del entorno. Siguiendo a Lakoff y Johnson (1998), la producción metafórica se basa en la percepción, las facultades psicomotrices y la experiencia "corporeizada". A partir de estos conocimientos, proyectamos vivencias y ordenamos lo que vemos, escuchamos o sentimos de acuerdo con estos patrones mentales. En este sentido, cuando decimos que una persona se parece a un animal o que los animales están presentes en nuestra cotidianidad, partimos de un esquema abstracto que, tal como vimos anteriormente, se denomina metáfora conceptual y de ella se originan una serie de expresiones metafóricas o metáforas particulares. Con el fin de ordenar el proceso cognitivo, Pamies propone cuatro niveles: el dominio meta, los dominios fuente o modelos icónicos, las archimetáforas y las metáforas particulares. Para el análisis de las metáforas zoonímicas del DCA, proponemos los siguientes niveles:

1. Dominio meta u origen: ANIMAL

2. Los dominios fuente o modelos icónicos:

1. El ser humano es un animal

2. El reino vegetal es un animal

3. Un animal es otro animal

3. Archimetáforas:

1.1. Una parte del cuerpo humano es un animal

1.2. El estado de ánimo es un animal

1.3. Las cualidades humanas positivas son como las de un animal 1.4. Las cualidades humanas negativas son como las de un animal 
1.5. El comportamiento humano es similar al de un animal

1.6. Las actividades cotidianas humanas son actividades zoonímicas

2.1. El reino vegetal está formado por partes de un animal

2.2. El reino vegetal pertenece a un animal

3.1. Los animales salvajes son animales domésticos

3.2. Dos animales forman un animal

3.3. Los animales son una característica

\section{Metáforas particulares}

El objetivo de esta clasificación, tal y como lo apunta Pamies (2002: 14), es conformar un numeroso inventario de metáforas que se desprendan de una idea común llamada modelo icónico, este modelo conformado por dominios debe corresponder a nociones universales o razonablemente susceptibles de serlo y debe incluir muchas metáforas particulares, por lo que se hace necesario contar con un nivel como el de las archimetáforas para clasificar cada grupo de alusiones metafóricas de acuerdo con las características de cada grupo. A continuación se analizan cada uno de los tres modelos icónicos propuestos: el ser humano es un animal, el reino vegetal es un animal y los animales son otros animales.

\subsection{Modelo icónico 1: El ser humano es un animal}

Según Echevarría (2009), una de las principales metáforas del español es "las personas son animales", esto por cuanto proyecta conceptos de un dominio origen (animal) a un dominio distinto (el ser humano), - las personas pueden ser o parecerse a un abejón, avispa, atarrá, buey, camarón, camello, calandria, curré, chía, chicharra, chiltote, chincha, chompipe, cuilo, esperanza, estucurú, ganso, cabro, gallo, gato, hormiga, lagartija, liebre, liendre, lora, loro, mapachín, mula, pajarito, pajuila, paloma, pato, pavo, perro, picuya, pijeje, pulga, pulpo, rata, tigre, timburil, tortuga, toro, totolate y vaca-, a otros dominios destinos según la virtud o característica que se quiera resaltar - una parte del cuerpo humano es un animal, el estado de ánimo es un animal, las cualidades humanas positivas son como las de un animal, las cualidades humanas negativas son como las de un animal, el comportamiento humano es similar al de un animal y las actividades cotidianas humanas son actividades zoonímicas-.

Incluso Agüero emplea como procedimiento lexicográfico la definición de lexemas simples que ayudarán a interpretar la motivación de los fraseologismos en que aparecen como constitutos esos vocablos; por ejemplo, antes de introducir en el artículo lexicográfico la frase parecer un pijije y su correspondiente definición, dio entrada a la palabra pijije con la respectiva definición, de modo que el sentido de esa frase zoonímica se hace amigable al lector. Veamos algunos ejemplos de las definiciones que da el diccionario a los lemas zoonímicos:

caballo. m. Hombre ignorante, necio, torpe, bestia. Agüero, (1996:43)

chivo. m. 2.fig.fam. Cornudo, hombre que vive con una mujer infiel. Hombre que vive con una ramera para que lo mantenga. Agüero, (1996:99)

elefante. $m$. Persona a quien le gustan las cosas gratuitas, sin pagarlas; que suele comer, beber, viajar, asistir a fiestas o espectáculos a costa de otro. Agüero, (1996:124)

gallina.2. fig. vulg. Muchacha, mujer joven. Agüero, (1996:155)

gallo. Hombre sobresaliente en un lugar o que domina en él. Agüero, (1996:156)

gato, ta. adj. Se dice de los ojos claros, azules, zarcos o garzos, y también de la persona que tiene los ojos de este color. Agüero, (1996:123)

mula.2.adj.fam.Torpe, tonto, necio.//3.Grosero en un juego deportivo, como el fútbol. Agüero, (1996:123)

pájara.2.fig.mujer casquivana, mujercilla. Agüero, (1996:238)

pájaro. m. fig. Hombre bribón, pillo, caco, pájaro de cuenta.//2.fig.fam. Homosexual, sodomita. Agüero, (1996:238) 
pajarón.2 fig.fam. Homosexual, sodomita. Agüero, (1996:238)

pajuila.2. fig.fam. Persona que tiene las piernas largas y delgadas. Agüero, (1996:238)

pijeje.2. fig. Hombre de piernas largas y flacas. Agüero, (1996:258)

pato. m. fig. Campesino, rústico, paleto.p.us. Agüero, (1996:240)

perro, rra. adj. Enamoradizo, muy adicto a enamorar mujeres con fines deshonestos, y en femenino, mujerzuela, prostituta. Agüero, (1996:254)

rata. com. Persona despreciable, vil, pilla, pícara. Agüero, (1996:278)

sapo, pa. adj. Entrometido.// Que curiosea, que tiene la mala costumbre de averiguar lo que no le importa.//m. Gendarme, esbirro, detective. Agüero, (1996:292)

tiburón, na. m. y fem. fig. y fam. Persona, voraz, acaparadora, egoísta, estafadora. Agüero, (1996:310)

tigra. fig. fam. Mujer iracunda, violenta, grosera. Agüero, (1996:311)

yegua. adj. fig. fam. Torpe, tonto, ignorante.//fig. fam. Grosero, que maltrata a otro bruscamente. Agüero, (1996:336)

zompopo, pa. adj. fig. fam. Dícese de la persona que tiene la cabeza grande.// 2.fig. fam. Torpe, lelo, tonto. (1996:337)

zorra. adj. fam. Torpe, inhábil, que no tiene capacidad para hacer una cosa o para aprender. Agüero, (1996:340).

Cada una de estas anotaciones ayudan al lector a interpretar el sentido de las frases zoonímicas y las dotan de los distintos modos en que la comunidad de habla asigna a los animales atributos y propiedades humanas.

A continuación nos referiremos al primer grupo de archimetáforas denominado "Una parte del cuerpo humano es un animal". Cuando a una persona se le dice que parece un curré, un estucurú, un pijeje o un timburil se está estableciendo una comparación con la totalidad del animal, sin embargo es una parte del cuerpo humano la que se está satirizando. Así, una persona es un curré (tucán) porque es narigón, una pajuila o un pijeje (pájaros de cuerpos pequeños y de patas largas y muy delgadas) porque tiene las piernas flacas, un timburil (pez que cuando se saca del agua se infla) porque la persona tiene la barriga muy grande. Otro ejemplo es el estucurú, búho que tiene un copete, por lo que a las personas que están despeinadas se les dice que parecen un estucurú. Así, si las personas tienen piernas delgadas son pajuilas o pijejes, si tienen la nariz aguileña son currés, si están despeinados o tienen un copete, son estucurúes y si tienen mucha barriga, timburiles.

En la archimetáfora $n .{ }^{\circ}$ 2, "el estado de ánimo es un animal", sobresale el enojo, asociado al color rojo como en parecer un chiltote (persona que tiene el rostro encendido como el pájaro que lleva este nombre), sangre de gallo y parecer un chompipe. También uno puede enojarse y parecerse una chincha; este insecto se caracteriza porque cuando se siente amenazado despide un olor fétido, o bien, parecer un toro guaco o ser un toro, animal agresivo que defiende enérgicamente su territorio, igual que la chía, avispa grande, negra y muy agresiva. Sobre este nivel, el dominio meta puede coincidir con el dominio CÓLERA, que a su vez se representaría con un modelo icónico como el de cuerpo + temperatura y la archimetáfora calentamiento. En las metáforas anteriores, el color rojo es producto del enojo. Al enojarse, los animales, ya sea por defensa o por ataque, concentran la mayoría de su flujo sanguíneo alrededor de sus órganos vitales, esto mediante la contracción de los vasos capilares. Tal hecho fisiológico hace que la piel se torne rojiza en el tórax y la cabeza. De ahí que cuando el toro bufa da la impresión que es producto de la concentración del calor en su cuerpo.

Sobre las cualidades humanas positivas que corresponden a la archimetáfora $n .^{\circ} 3$, las metáforas se construyen a partir de la identificación de la capacidad que caracteriza a ciertos animales. Los animales que destacan por su capacidad para el trabajo, la valentía, su buen carácter o su agilidad son: la hormiga, la avispa, el camello, la mula, el gallo, el cabro, el tigre, el águila y la paloma. Así, tenemos 
que el cabro es hábil para subir lugares altos, el gallo es esforzado y muy valiente; la hormiga, la mula y la avispa son hacendosas, activas y trabajadoras; la liebre es lista y sagaz; el águila y el tigre son ágiles desde el aire y la tierra; la paloma es de buen carácter y el camello sobresale por su capacidad de trabajo. Es importante resaltar que mientras ocho animales son portadores de habilidades, veintidós tienen connotaciones negativas: abejón, atarrá, buey, calandria, camarón, chicharra, esperanza, ganso, gato, lagartija, liendre, lora, mapachín, pajarito, pato, perro, pavo, picuya, pulga, pulpo, tortuga, totolate, vaca. Las metáforas que tienen connotaciones negativas se refieren a la lentitud, a situaciones difíciles, ser pequeño, tener la voz ronca, la cobardía, ser vagabundo, la terquedad, hablador, ser inquieto, ser flaco, canoso o a ser acaparador. Cabe resaltar que este tipo de metáforas son lingüísticamente más complejas que las anteriores. Las metáforas que nos hablan de la apariencia física, las cualidades positivas y estados de ánimo poseen una composición gramatical similar: verbo ser o parecer más un sustantivo zoonímico; sin embargo, las metáforas que tienen connotaciones negativas son más complejas desde el punto de vista gramatical y semántico; por ejemplo: la esperanza es un insecto nocturno de color verduzco transparente, es por esta razón que se compara el color del insecto, con las personas que padecen alguna enfermedad y por esta razón se encuentran pálidos y débiles. Se dice que alguien se parece a una lagartija porque es muy delgada o un mapachín porque su cabello está canoso y se parece a la piel de este animal. Otros ejemplos son: parecer una carreta sin bueyes (lento, lerdo), ser (algo) un camarón muy feo (algo difícil), chicharra (orinarse mucho), cuilo (tener muchos hijos), ser un gallito fino (muchacho buscapleitos, ser como espulgar un gato negro (difícil, complicado), ser un asunto color de hormiga (ser difícil, peligroso, crítico), ganso (ser acaparador), ser un gato (algo difícil, complicado), liendre (ser poca cosa, ser cobarde, no valer nada), lora (ser muy parlanchín), loro (parlanchín, locuaz), pajarito (niño pequeño, comer poco), picuya (ser terco), pulga (ser pequeño e insignificante), pulpo (acaparador), tortuga (ser lento), vaca (ser torpe, ignorante), parecer que uno tiene totolate (estar inquieto), ser el pato de la fiesta (ser la vaca de la boda), parecer un pleito de perros (discusión acalorada), no ser comida de pavo (no ser nada fácil), ser una vaca echada (vagabundo).

Las expresiones metafóricas que se relacionan con comportamientos son igualmente complejas desde el punto de vista semántico. El ser humano puede comportarse como: un chancho, una chincha, una chisa, una gallina, un gallo, una gallina, una gata, un gato, un jején, una lora, un mico, un mosca, un pajarito, pájaro, un perro, un piche, un pizote, un sapo, un toro, una tortuga y un zorro. La elección de un determinado animal como representación de una característica depende de una colectividad. Por ejemplo, hacerse el gallo, significa hacerse el valiente, el retador, mientras que tener la carne de gallina implica ser miedoso. Sobre los atributos dados al gato y la gata ocurre algo similar: del macho, se exalta la agilidad como en defenderse como gato panza arriba y hacerse el gato bravo mientras que en la hembra se señala su capacidad reproductiva como en andar como gata de parto (andar inquieto) o estar como gata de parto. Sobre el chancho y el sapo, las frases mencionan su torpeza; la mosca y el perro sobresalen su capacidad para fingir como en mosca muerta y renquera de perro, etc.

Existen una gran cantidad de metáforas zoonímicas relacionadas con la vida cotidiana, tal y como lo podemos observar en el Esquema 2. La cotidianidad, según las metáforas de este núcleo generador, nos habla de una vida que gira en torno al patio. El patio era un espacio ubicado alrededor de las casas de la Costa Rica dedicada a la agricultura; en él generalmente; se ubicaban los corrales de los cerdos, las vacas, los caballos y los gallineros. Por esta razón creemos que las actividades cotidianas humanas descritas en el corpus están relacionadas con animales domésticos y animales que se acercaban frecuentemente al patio de las casas como el pizote, el zorro, las avispas y los monos. La cantidad de veces que aparecen estas alusiones metafóricas son: (9) chancho, (6) gallo, (5) perro, (5) vaca, (4) caballo, (3) toro y (3) buey. 
Como se comentó al inicio de este apartado, las metáforas son inspiradas por las experiencias de vida, por el entorno y por muchas horas de contemplación. Así que, si bien es cierto estas metáforas de la cotidianidad surgen del concepto general "animal", tienen enlaces con otros conceptos. Veamos los siguientes casos:

El chancho es asociado con estupidez: coger a uno de chancho, saber más una chancha de ..., saber tanto como chancha; con comer, como en: el peor chancho se lleva la mejor mazorca, el que muchos chanchos cría, ninguno se come y al chancho con lo que lo crían. Por su parte, la chancha está relacionada con dificultad: ahora si la chancha torció el rabo, aquí la chancha torció el rabo, ... torcer el rabo a la chancha.

El mono o mico representa humor: coger a uno de mica, ir a freir micos, amarrarse una mona, apearse o no la mona, clavarse una mona, ir a freír monos, ¡vaya a freír monos a otra parte!

El gallo y gallina se relacionan con el ámbito de la cocina como en comer gallina, cortarle a uno la gallina, gallo tapado, pegársele a uno el gallo, estar pensando en los huevos del gallo.

El perro y la perra se asocia con la desgracia y el infortunio: suerte perra, al perro flaco se le pegan las pulgas, amarrar el perro, no cagar para que los perros no coman, parecer un pleito de perros.

La vaca se asocia con la estupidez: chupado de la vaca, haberlo a uno chupado la vaca, mamado de la vaca; si no es vaca, es toro.

El caballo se relaciona con la grandeza: caballo regalado no se le busca colmillo, cola de caballo, estar uno en caballo blanco, ir uno a caballo.

El buey se asocia con la pasividad: pegar bueyes, ¿a dónde ha de ir el buey que no are?, comer un buey y no eructarlo.

El toro se relaciona con situaciones difíciles y el peligro: agarrar a uno el toro, coger a uno el toro, ver los toros desde la barrera.

A continuación se presenta la Tabla 1 , en el cual se detalla el primer modelo icónico titulado "El ser humano es un animal".

TABLA 1

ANIMAL

Modelo icónico 1

El ser humano es un animal

\begin{tabular}{|c|c|c|c|c|c|}
\hline Archimetáfora 1 & Archimetáfora 2 & Archimetáfora 3 & Archimetáfora 4 & Archimetáfora 5 & Archimetáfora 6 \\
\hline $\begin{array}{l}\text { Una parte del } \\
\text { cuerpo humano es } \\
\text { un animal }\end{array}$ & $\begin{array}{l}\text { El estado de ánimo } \\
\text { es un animal }\end{array}$ & $\begin{array}{l}\text { Cualidades } \\
\text { humanas positivas } \\
\text { son como las de un } \\
\text { animal }\end{array}$ & $\begin{array}{l}\text { Cualidades } \\
\text { humanas } \\
\text { negativas son } \\
\text { como las de un } \\
\text { animal }\end{array}$ & $\begin{array}{l}\text { El comportamiento } \\
\text { humano es similar al de } \\
\text { un animal }\end{array}$ & $\begin{array}{l}\text { Las actividades } \\
\text { cotidianas } \\
\text { humanas son } \\
\text { actividades } \\
\text { zoonímicas }\end{array}$ \\
\hline metáfora particular & metáfora particular & metáfora particular & metáfora particular & metáfora particular & metáfora particular \\
\hline $\begin{array}{l}\text { - Nariz de curre } \\
\text { - Parecer uno un } \\
\text { curré } \\
\text { - Parecer una } \\
\text { pajuila } \\
\text { - Parecer un pijije } \\
\text { - Parecer un } \\
\text { timburil }\end{array}$ & $\begin{array}{l}\text { - Parecer un } \\
\text { chompipe } \\
\text { - Parecer un toro } \\
\text { - Parecer un toro } \\
\text { guaco } \\
\text { - Estar chivito } \\
\text { - Estar como un } \\
\text { chompipe } \\
\text { - Tener uno malas } \\
\text { pulgas }\end{array}$ & $\begin{array}{l}\text { - Parecer una } \\
\text { hormiga } \\
\text { - Ser muy liebre } \\
\cdot \text { Ser un tigre } \\
\text { - Ser una casta } \\
\text { paoma } \\
\text { - Mula de carga } \\
\text { - Ponerse águila }\end{array}$ & $\begin{array}{l}\text { - Parecer un abejón } \\
\text { - Parecer un atarrá } \\
\text { - Parecer una } \\
\text { carreta } \\
\text { - Parecer una } \\
\text { calandria } \\
\text { - Ser muy calandria } \\
\text { - Un camarón } \\
\text { muy feo } \\
\text { - Parecer una } \\
\text { chicharra } \\
\text { - Parecer una } \\
\text { esperanza } \\
\text { - Ser ganso } \\
\text { - Ser como espulgar } \\
\text { gato negro }\end{array}$ & $\begin{array}{l}\text { - Caer de chancho } \\
\text { - Hacerse el chancho } \\
\text { - Hacerse el chancho para } \\
\text { que lo lleven en carreta } \\
\text { - Hacerse el chancho para } \\
\text { ponerse a gusto } \\
\text { - Queda uno como un } \\
\text { chancho } \\
\text { - Estar como una chincha } \\
\text { - Correr más que una } \\
\text { chisa } \\
\text { - Tener carne de gallina } \\
\text { - Hacerse el gallo } \\
\text { - Andar como gata de } \\
\text { parto }\end{array}$ & $\begin{array}{l}\text { - A dónde ha de ir } \\
\text { el buey que no are? } \\
\text { - Comer un buey y } \\
\text { no eructarlo } \\
\text { - Jinetear la burra } \\
\text { - A caballo } \\
\text { regalado no se le } \\
\text { busca colmillo } \\
\text { - Cola de caballo } \\
\text { - Estar uno en } \\
\text { caballo blanco } \\
\text { - Ir uno a caballo }\end{array}$ \\
\hline
\end{tabular}




\subsection{Modelo icónico 2: El reino vegetal es un animal}

Dentro de la gran gama de metáforas relacionadas con los animales, encontramos un grupo que define variedades de plantas y vegetales como si fueran animales, tal y como se puede observar en el Esquema 3. Estas metáforas se llevan a cabo mediante la comparación de una parte del cuerpo de un animal con la forma de la planta o porque la planta ha sido identificada como alimento del animal, por lo que se da una relación de pertenencia.

Sobre las comparaciones de una parte del animal con las características de la planta, los hablantes del español de Costa Rica, escogieron ciertas partes como: ojo, cola, boca, cresta, pata, rabo, uña, diente, mano, canilla, cara, ala, pico, pie, colmillo, pelo, lengua, cacho y casco. En el corpus encontramos: ojo de buey y ojo de venado; cola de alacrán, cola de caballo, cola de león, cola de pescado, cola de venado y cola de zorro; boca de dragón, de león; cresta de gallo; pata de gallo; rabo de gato, de mico, rabo de ratón, rabo de puerco; uña de gato, etc. Todas estas metáforas son producto de analogías que han establecido los hablantes con aparentes similitudes que tiene las plantas con una parte del animal, por ejemplo, la imagen 1 es una fotografía de la planta conocida como

\section{IMAGEN 1}

Cacho de venado

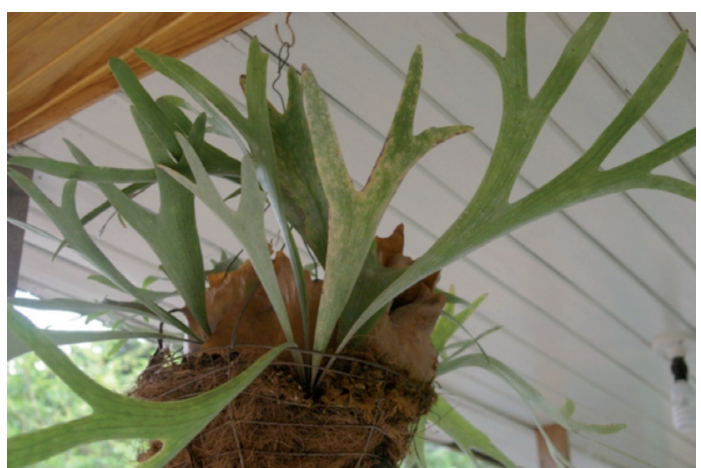

Fuente: colección personal. cacho de venado; se llama así porque sus hojas son similares a los chachos de un venado, igual sucede con la planta cara de mula de la imagen 2 :

\section{IMAGEN 2}

Cara de mula

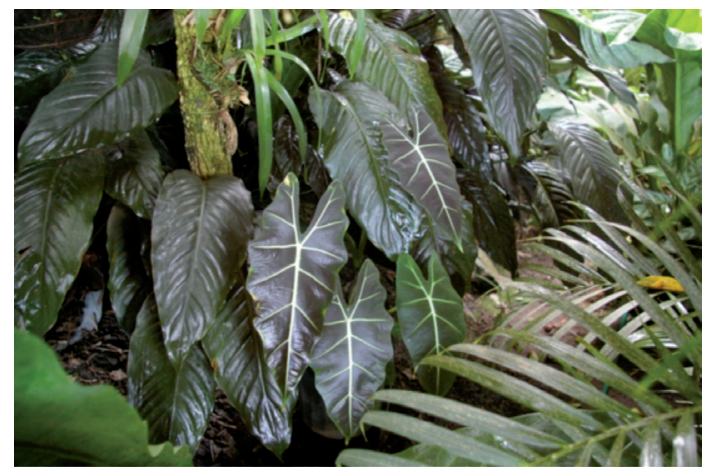

Fuente: colección personal.

En la archimetáfora "el reino vegetal pertenece a un animal", una comunidad de hablantes, mediante la observación, determinó que una planta o un fruto como el culantro de coyote, zapote de mico, papa de venado, papaya de venado eran comidos por estos animales y así fueron nombradas. Por ejemplo, chile de perro se define como "una mala hierba de hojas y florecillas muy picantes; crecen en lugares húmedos, y se llaman así porque los perros las comen cuando tienen dolor de estómago" (Agüero, 1996: 95) y guineo de chancho como una "especie cuyas frutas se usan exclusivamente para alimentar a los cerdos" (Agüero, 1996: 166). Aunque no todos las referencias especifican que la planta y el fruto hayan sido alimentos preferidos o consumidos por los animales, reconocemos la información que manejan las personas de campo sobre la naturaleza. Véase la Tabla 2. 
TABLA 2

ANIMAL

Modelo icónico 2

El reino vegetal es un animal

\begin{tabular}{|c|c|c|}
\hline & Archimetáfora 1 & Archimetáfora 2 \\
\hline & $\begin{array}{c}\text { EI reino vegetal está formado por } \\
\text { partes de una animal }\end{array}$ & $\begin{array}{c}\text { El reino vegetal pertenece a un } \\
\text { animal }\end{array}$ \\
\hline & metáfora particular & metáfora particular \\
\hline • & Cola de alacrán & Cacao de ardilla \\
\hline • & Ojo de buey & Lirio de caballo \\
\hline • & Cola de caballo & Mozote de caballo \\
\hline - & Boca de dragón & Café caracolillo \\
\hline - & Cola de gallo & Culantro de coyote \\
\hline - & Cresta de gallo & Zacate cola de coyote \\
\hline - & Pata de gallo & Bejuco de culebra \\
\hline • & Rabo de gato & Comida de culebra \\
\hline • & Uña de gato & Guineo de chancho \\
\hline • & Huevos de perro & Palo de chancho \\
\hline • & Boca de león & Corteza de chivo \\
\hline - & Cola de león & Maíz de gallo \\
\hline - & Diente de león & Piñuela de garrobo \\
\hline - & Mano de león & Hoja de lapa \\
\hline • & Rabo de mico & Piñuela de mico \\
\hline • & Canilla de mula & Zapote de mico \\
\hline • & Cara de mula & Papaya de mico \\
\hline • & Ala de murciélago & Fruta de mono \\
\hline - & Pico de pájaro & Zacate de mula \\
\hline • & Pie de paloma & Hoja de pájaro \\
\hline • & Pico de gato & Hoja de pato \\
\hline • & Colmillo de perro & Chile de perro \\
\hline • & Cola de pescado & Zacate de ratón \\
\hline - & Colmillo de puerco & Bejuco de sapo \\
\hline - & Rabo de puerco & Raíz de toro \\
\hline - & Pelo de ratón & Papa de venado \\
\hline - & Rabo de ratón & Papaya de venado \\
\hline - & Mano de tigre & \\
\hline - & Lengua de vaca & \\
\hline - & Cola de venado & \\
\hline - & Cacho de venado & \\
\hline • & Ojo de venado & \\
\hline • & Cola de zorro & \\
\hline
\end{tabular}




\subsection{Modelo icónico 3: El animal es otro animal}

Finalmente, proponemos como tercer modelo icónico del concepto animal, tres archimetáforas: los animales salvajes son animales domésticos, los animales son una característica y dos animales forman un animal. Sobre la primera, el mecanismo utilizado para construir las metáforas es acercar lo visto en el mundo conocido, a lo cercano para los hablantes. $\mathrm{Si}$ el hablante observa un animal salvaje no identificado, tratará de compararlo con un animal doméstico; por ejemplo, cabro, chancho, gallina y pava de monte, gallina de palo, caballito de mar, perro de agua, etc.

La segunda archimetáfora, ver Esquema 3, plantea que los animales deben tener una característica que los identifique de otros de la misma especie. La gran cantidad de animales que existen en Costa Rica ha presionado a sus habitantes a crear nuevas formas de nombrar y diferenciar todas esas especies. Uno de estos casos son las hormigas, las encontramos negras, rojas, amarillas con alas, pequeñas y grandes, las que pican y las que solo corren por todas partes. En el corpus encontramos las hormigas agrias (ponzoñosas), hormigas locas (las que andan de prisa y en todas las direcciones) y hormigas zompopas (roja, grande y cabezona) y las serpientes: culebra sabanera (inofensiva que se encuentra en los matorrales), culebra rabo amarillo (víbora venenosa de color pardo con el extremo de color amarillento), culebra terciopelo, culebra de sangre (víbora cuya picadura, produce abundante hemorragia por los poros), culebra coral, culebra bejuquilla. Otros ejemplos de este tipo son perro faldero, víbora de sangre, araña picacaballo y zorro hediondo.

En la tercer archimetáfora ubicamos a las expresiones metafóricas que se construyen utilizando dos sustantivos zoonímicos. Por ejemplo: culebra lora, culebra zopilota, y culebra mica. En estos casos la serpiente adquiere las características de la lora y el zopilote por sus colores, y de la mica porque, según las personas de campo, se lanza desde las ramas de los árboles sobre quienes pasan por debajo de estos.

Como hemos visto, las caracterizaciones de los animales requieren de un profundo conocimiento sobre su hábitat, sus peligros y sus atributos positivos. Las personas que se han apropiado de estas frases tenían un dominio de su entorno y podían referirse con propiedad sobre la naturaleza que los rodeaba. Esta información, que ha quedado en las frases zoonímicas del DCA, ilustra el aporte cultural que hace el diccionario al estudio de las identidades que conforman el imaginario llamado Costa Rica. Podemos concluir que las metáforas vinculadas con los tres modelos icónicos propuestos: el ser humano es un animal, el reino vegetal es un animal y el animal es otro animal, son el producto del análisis de las experiencias de vida del campesino de la Costa Rica del siglo XX, hasta la década de los setenta. A partir de la observación, los hablantes construyeron las metáforas zoonímicas con el fin de expresar características del mundo animal en otros espacios como el vegetal y el humano, porque, tal y como lo dice Quignard (1998:30): “una lengua es aquello por lo que una sociedad se interna en la naturaleza. Propiamente hablando, la lengua no prolonga lo que es. Exterioriza. Introduce lo afuera en una plenitud". 
TABLA 3

ANIMAL

Modelo icónico 3

El animal es otro animal

\begin{tabular}{|c|c|c|}
\hline Archimetáfora 1 & Archimetáfora 2 & Archimetáfora 3 \\
\hline $\begin{array}{l}\text { Los animales salvajes son } \\
\text { animales domésticos }\end{array}$ & $\begin{array}{l}\text { Los animales son } \\
\text { una característica }\end{array}$ & Dos animales forman un animal \\
\hline metáfora particular & metáfora particular & metáfora particular \\
\hline - Cabro de monte & - Araña pica caballo & - Oso caballo \\
\hline - Chancho de monte & • Gallo giro & - Culebra lora \\
\hline - Gallina de ciénaga & - Gallo de patio & - Culebra mica \\
\hline - Gallina de monte & - Gallo tapado & - Culebra zopilota \\
\hline - Gallina de palo & - Hormiga agria & \\
\hline - Pava de monte & - Hormiga lora & \\
\hline - Caballito de mar & • Hormiga zompopa & \\
\hline - Piojo de ropa & - Lapa colorada & \\
\hline - Perro de agua & - Lapa verde & \\
\hline \multirow[t]{13}{*}{ - Concha de vaca } & - Ju de León & \\
\hline & - Mula del diablo & \\
\hline & - Oso real & \\
\hline & - Pájaro bobo & \\
\hline & - Pava granadera & \\
\hline & - Perico ligero & \\
\hline & - Perro faldero & \\
\hline & - Toboba chinga & \\
\hline & - Toboba de uña & \\
\hline & - Víbora de sangre & \\
\hline & - Rey zopilote & \\
\hline & - Zorro hediondo & \\
\hline & - Zorro pelón & \\
\hline
\end{tabular}

\section{Bibliografía}

Agüero Chaves, A. 1996. Diccionario de Costarriqueñismos. San José: Asamblea Legislativa.

Echevarría Isusquiza, I. 2003. Acerca del vocabulario español de la animalización humana. Recuperado de http://www.ucm. es/info/circulo/no15/echeverri.htm el 20 de enero del 2009.
Kekié, K. 2008. El lenguaje figurado con zoonímicos en serbio. Language Design, (10). Recuperado de elies.rediris. es/ Language_Design/. ../LD_10_04_Kekic _Pazeado.pdf el 20 de enero del 2011.

Lakoff, G. y Johnson, M. 1998. Metáforas de la vida cotidiana. Madrid: Ediciones Cátedra S.A.

Olza Moreno, I. 2009. Metáfora y conocimiento del lenguaje: fraseología somática 
metalingüística. Recuperado de www. unav.es/linguis/olza/Buske.pdf el $7 \mathrm{de}$ mayo del 2011.

Pamies Beltrán, A. 2002. Modelos icónicos y archimetáforas: algunos problemas metalingüísticos en el ámbito de la fraseología. Language Design, (4). Recuperado de elies.rediris.es/Language Design/LD4/pamies.pdf el 7 de mayo del 2011.

Pérez Bernal, M. 2004. Fraseología y metáfora. Materiales para la enseñanza de la fraseología en una L2. Recuperado de http://cvc.cervantes.es /enseñanza/ biblioteca_ele/asele/pdf/15/15_0644.pdf el 7 de octubre del 2009.

Quignard, P. 1998. El odio a la música. Santiago de Chile: Editorial Andrés Bello.
Sánchez Mora, A. 2007. Creación metafórica y lexicográfica en el Diccionario de costarriqueñismos de Arturo Agüero. Káñina Revista de Artes y Letras de la Universidad de Costa Rica, XXXI (1), 145-153.

Tristá Pérez, A. M. 1985.La metáfora: sus grados de revelación en las unidades fraseológicas. En Estudios de fraseología (47-65). La Habana: Academia de Ciencias de Cuba, Instituto de Literatura y Lingüística.

Tutáeva, K. 2009. La simbología del cerdo en la fraseología inglesa, rusa y española. Language Design, (11). Recuperado de elies.rediris.es/Language_Design / LD11/LD11-01-Tutaeva.pdf el 20 de enero del 2011. 
